\title{
Trust and Power as Means of Co-ordinating the Internal Relations of the Organization - A Conceptual Framework
}

\author{
R. Bachmann
}

SOM-theme G: Cross-contextual Comparison of Institutions and Organizations

\begin{abstract}
This paper provides a conceptual framework for analysing trust and power in the internal relationships of the organization. It adopts a neo-institutionalist view focussing on the structural inventory and the social embeddedness of the organization in the process of developing trust between its individual members. It is suggested that, based on specific combinations of factors rooted in the internal social structure as well as the external socio-economic environment of the organization, two divergent trust/power control patterns emerge as ideal-typical forms of coordinating expectations and interaction among organizational actors.
\end{abstract}


The problem of co-ordinating individual actors' activities within the boundaries of the organization is certainly one of the key issues of organizational theory. Irrespective of whether the nature of the organization is seen as primarily based on contractual arrangements, shared social norms, constellations of economic interests or common cultural orientations, the question of how to integrate different actors' expectations and interaction lies at the heart of any organization's identity. If this function is not fulfilled satisfactorily, organizations will be confronted with serious problems which make it unlikely that they will survive over a longer period of time. However, the simple fact that stable organizations $d o$ exist, and even more so, that many of them are quite successful with their activities, can be taken as a strong indication that this co-ordination problem can be tackled and in fact is effectively solved every day all around the globe. Undoubtedly, organizations can also look chaotic and indeed may collapse where too many divergent interests render these uncontrollable. But it is an indisputable and - in a theoretical perspective - more remarkable observation that in countless cases complex organizations exist in a stable manner, operate profitably, develop their businesses, and even survive when their strategies need to be radically redefined where far-reaching changes in the business environment forces them to do so (Luhmann 1984).

In this paper, it will be argued that a fruitful approach to understanding the coordination of expectations and interaction within organizations, builds on the insight that there must be certain social mechanisms at work which allow for a swift and relatively frictionless alignment of its individual members' behaviour. It will be suggested that trust and power are efficient means to do this job. This paper will show how these mechanisms function, what are the preconditions and consequences of employing them, and how they can be inter-linked and thus provide specific regimes of organizational control. Section 2 of this contribution will deal with the nature and various forms of trust as well as with the role of power in organizational relations, while section 3 will discuss two different types 
of organizational regulation building on the specific sort and combination of trust and power that occurs in organizational relationships. The conclusion will be a short summing-up of the argument presented in this chapter.

\section{Trust}

\subsection{The nature of organizational trust}

As a theoretical starting point, the social mechanism of trust may be conceptualized as being based on a decision by which one social actor selects a specific positive assumption among a large number of other - in principle equally possible - assumptions about the future behaviour of another social actor (Luhmann 1979). The proactive party, i.e. the trustor, makes this selection, communicates it to the trustee and builds his own behaviour onto this assumption. He signals that he is prepared to make decisions generous and favourable to a trustee under the condition of limited knowledge of alter ego's motives and abilities as well as the impersonal circumstances in which this individual will behave in the future (Nooteboom 2002a). In doing so, he makes a pre-commitment assuming that the other party will not behave opportunistically. Although far from having any guarantees, a trustor chooses to assume that the trustee will simply not take advantage of his vulnerability resulting from his one-sided pre-commitment, and ignores the rest of other possibilities.

Such a pre-commitment need not necessarily be solely interpreted with regard to its normative implications. Often such a behaviour is eminently important to simply provide a first step to initiate any form of social interaction between two actors (Bachmann 2001). Where none of the parties finds itself able to offer a one-sided commitment in advance, it may well be that no social communication at all will arise between them. Where one actor, however, makes this first step, the second actor will also be able select specific assumptions with regard to the first actor's future behaviour and 
discard the rest of other possibilities. Thus, specific expectations can be selected on a mutual basis, a large number of theoretically equally expectable possibilities of each actor's future behaviour are rejected, and long chains of co-ordinated social interaction, i.e. complex social systems, can emerge. Trust, in other words, facilitates the coordination of expectations and allows for meaningful complex interaction between individuals who might otherwise have little chance to engage in any kind of social relationship.

Unlike other mechanisms of co-ordinating expectations and interaction between two social actors, trust unavoidably requires an extrapolation from the available information on part of the initiative individual, i.e. the trustor. As he has no guarantees as regards the future behaviour of the trustee he will necessarily have to bear a certain amount of risk as soon as he decides to invest trust in a social relationship. On the one hand, an actor's decision to offer trust as the prime co-ordination mechanism within a relationship diffuses uncertainty that would otherwise characterise the situation and paralyse the two potential interactors. But, on the other hand, it also produces a binarily coded risk: the trust investment will either pay off or the trustee will misuse the trustor's pre-commitment and not reciprocate any favours.

Given this inherent characteristic of trust, it seems evident that social actors who consider this mechanism as a possible basis for their interaction with another actor usually seek reasons as to why the risk of trust will at least not exceed certain - more or less acceptable - limits. Although trust can never be built on complete information - since it would make itself superfluous in this case - sensible trustors are, by the same token, not keen to invest 'blind trust'. The latter is not likely to win any social admiration (especially not if it fails). Potential trustors usually try to roughly assess the risk that they would buy into with their decision to invest trust in a relationship and then decide whether or not they are prepared to bear this risk. Social actors, thus, tend to make limited investments of trust. They may, in their everyday routines, be far from basing their decisions always on explicit and quantifiable calculation but, at the same time, it would 
be unrealistic to assume that there are many cases where they have no consciousness of the consequences of their behaviour at all.

If this is so, then one of the most crucial subsequent questions is: what can provide good reasons (Bachmann 2001) for a (potential) trustor to believe that the risk he needs to accept when making a trust investment in the form of a pre-commitment will not exceed a certain limit of acceptability? Following Luhmann's argument (1979), the existence or absence of legal norms may be seen as playing a central role in many situations where trust is considered as the dominant co-ordination mechanism in a social relationship. In an environment where clear and reliable legal norms exist, a potential trustor has good reasons to assume that the potential trustee, who also knows these norms, will generally be discouraged from cheating. It is presupposed, however, that the sanctions connected with these legal norms remain latent. In other words, trust requires that these sanctions are not considered explicitly by the trustee and that the potential trustor does not refer to them with the intention of threatening the potential trustee. The mobilisation of sanctions is seen as playing a role only in exceptional cases which neither the trustor nor the trustee expects to become reality. Normally, it seems sufficient if social actors orient their behaviour along the lines of the existing legal arrangements. If social actors simply accept these without too much critical reflection on worst case scenarios, legal norms do a perfect job. Under these - and only under these! - conditions legal norms can be seen as an important pre-requisite to foster the production of trust in social relationships.

Applying this conceptualization of the trust mechanism to the world of social relations within organizations sheds light on the function of social rules that are incorporated in the structure of the organization rather than on legal norms that may exist in the institutional environment of the organization. These intra-organizational social rules are represented, for example, in the patterns of division of work and the distribution of responsibilities, the agreements on work duties of each individual member of the 
organization etc. Also, they include forms of conflict resolution (Wittek 2002) and various other arrangements and practices that may evolve within the boundaries of the organization. All of these are elements of what could be called the structural inventory of the organization. Similar to how extra-organizational legal norms do their job with regard to individuals' behaviour, these intra-organizational social rules constitute the internal structural framework of the organization which channels each individual's behaviour according to the identity and dynamics of the organization as a whole. In that these rules have a normative dimension, they imply the potential for sanctions which may be used against individual actors who do not comply. Under usual circumstances, however, these sanctions - similar to legal norms existing in the external environment of the organization - are not activated. Their potential to sanction individuals' (mis-)behaviour is strong enough to direct individuals' decisions effectively towards certain channels of acceptable behaviour. Explicit threats with sanctions usually seem unnecessary. Where this happens, it constitutes an exceptional situation; if it occurs repeatedly, it may eventually result in a severe crisis, making a fundamental restructuring of the organization's institutional inventory likely and sometimes unavoidable.

The central function of the rules implied in the structural inventory of the organization is to provide shared social and cultural meaning as well as a common set of interpretation categories as regards economic and technical knowledge. This produces a world-in-common which - with regard to building trust - plays an eminently important role in organizations. Where the structural inventory of an organization is stable and reliable, their individual members are more likely to find good reasons to believe that the risk of investing trust in their relationships with other actors of the same organization is relatively low. The way a potential trustee will behave in the future is simply easier to predict under these circumstances than it is where such a 'world-in-common' is not in place. A strong internal regulation of the organization, in other words, will reduce the inherent risk of trust considerably. Where the structural inventory of the organization is fuzzy and unreliable, it is likely that individual actors will be less inclined to invest trust 
in their relationships to each other. It simply seems hazardous to invest trust where no or few shared orientations exist and the future behaviour of a colleague, a supervisor or a subordinate worker is difficult to foresee.

This theoretical approach to understanding trust in intra-organizational relations, which has been developed in the present contribution so far, draws substantively on Luhmann's systems theoretical reflections (1979). It also is inspired by conceptual notions developed within the framework of New Institutionalism (Powell and DiMaggio 1991; Scott 1995). At least the following three basic features of the phenomenon of trust are agreed by both of these theoretical traditions:

Trust deals with the problem of predicting another social actor's future behaviour. It is - to use Simmel's words - a state of mind, somewhere between knowing and not knowing (Simmel 1950) what a potential trustee will do in the future. It is a specific characteristic of trust that it provides a way of bridging this gap by accepting risk.

- $\quad$ It is legitimate and most likely that a potential trustor will seek possibilities to reduce the risk he needs to bear when investing trust. The risk cannot be calculated in exact terms but there must exist good reasons to assume that the inherent risk of trust will not exceed certain limits. Otherwise, trust is not justified and will usually not occur. Apart from the potential trustees' goodwill and abilities to perform according to the potential trustor's expectations, the institutional framework in which the possible relationship between the two parties will be embedded (Granovettor 1985 ) is very important with regard to whether the trustor will decide to invest trust or to refrain from doing so. 


\subsection{Different forms of trust}

The theoretical literature on trust makes an important distinction between two fundamental forms of trust: personal trust and impersonal trust. While an everyday understanding of trust tends to see it as a phenomenon that emerges in an intimate relationship between two individuals, many scholars emphasize the role of impersonal trust, particularly in the field of organizational relations. One of the central problems with the latter form of trust, however, seems to be that there exist divergent notions as to whether this concept should refer to the object of trust or to the environment in which individuals' social relationships are embedded. In the first case, the understanding is that individuals trust in systems of cultural or institutional rules. In the latter case, individuals are assumed to trust each other in the face of the structural arrangements surrounding them. Clearly, these two concepts differ significantly and, thus, at least three forms of trust might be worth discerning:

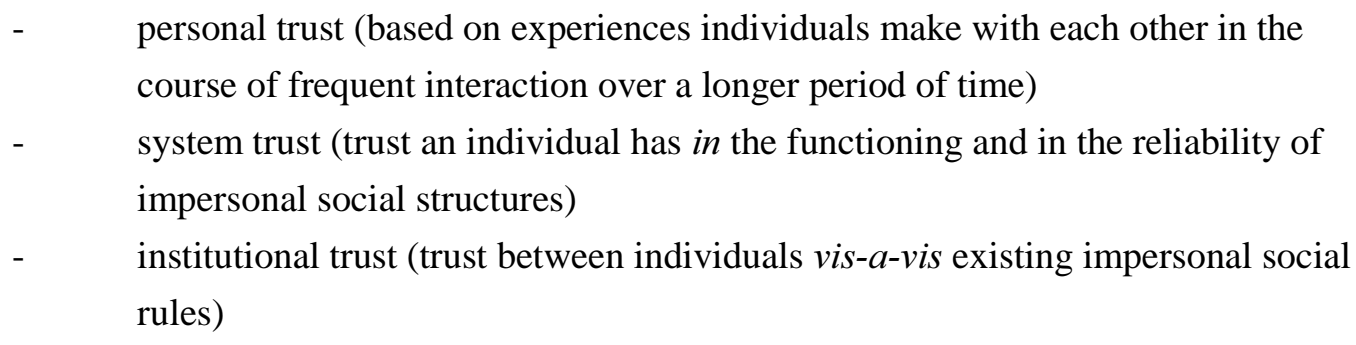

The concept of personal trust comes closest to the ordinary language connotations of trust. It can be fostered by frequently using opportunities to have face-to-face contacts between individual actors. The usual proximity of workplaces within organizations can be seen as a seedbed for developing this form of trust. It is often much more difficult to establish it in the organization's external relationships where personal contacts are often much rarer. But even within organizations the problem with this form of trust is that it 
takes a lot of time to grow. Also, in many cases it is as such not sufficient to effectively co-ordinate expectations and interaction between individuals, especially not in large and complex organizations. Nonetheless, it is a form of trust which is and remains important in social relationships. There seems to be strong indication that this form of trust, with the decline of the bureaucratic organization model, has gained renewed importance in many social relationships within organizational contexts (Ebers 1997; Lane and Bachmann 1998).

System trust is a phenomenon that is deeply rooted in anthropological conditions of human behaviour. While individuals unavoidably must have confidence - as Luhmann (1988) proposes to say here - in certain rules (e.g. natural laws) and authorities (e.g. parents, from a child's perspective), this form of trust has also become increasingly important today for a number of man-made, i.e. technical and social, artifacts which in modern times take on a character quite similar to those which can be viewed as the really unalterable conditiones humanae. With reference to this observation, Giddens (1990) argues that modern societies constitutively depend on lay individuals' preparedness to have trust in 'abstract systems' operated by highly specialised experts. Trust in the safety technology and procedures in the commercial aviation industry - to mention an example used by Giddens (1990, p. 85) himself - is simply a precondition for many people's need to swiftly travel long distances today. Although very few passengers have any idea about why flying on airplanes can be considered one of the safest ways to travel, they - even after having seen the horror scenes of hijacked planes crashing into New York's World Trade Center - do trust in the aviation safety systems and the experts who develop and operate them, just like they trust religious leaders and the law of gravity, or like little children unquestioningly trust their parents.

In similar vein, system trust that exists within organizations builds on the authority attributed to formal social positions as well as on the reliability of technical systems, standards and procedures. For example, employees of an organization that operates within a strongly hierarchy-based business environment may have the strongest 
belief that their employer will always make decisions which are to their benefit. Similarly, the workers at an atomic plant may have the infallible believe that the technology they are dealing with simply cannot fail because generations of experts have made the greatest efforts to prevent any possibility of failure. The latter example illustrates particularly well that the object of system trust is usually a large abstract system which primarily exists at the societal level reaching into the organizational world from its external environment (Bachmann 2000).

One of the most interesting phenomena associated with this form of trust is that once in a while some representatives of the systemic abstract authorities whose activities are, in normal circumstances, largely withdrawn from their clients', customers' or workforce's awareness, become touchable. The purpose of this is to reassure these individuals that their trust is targeted to responsible social actors who are actually in control of the systems they stand for. This is why pilots occasionally speak to their passengers, eloquent nuclear scientists appear in TV talk shows and powerful entrepreneurs as well as high ranking managers of large corporations suddenly become equal to the lowest paid cleaner in their organization when sitting next to him at the occasion of a Christmas party. In all these situations individuals lend a personal flavour to the unknown abstract worlds of superior knowledge and power confirming that these deserve to be trusted. Without these boundary-spanning roles being competently performed at suitable occasions, it would be doubtful that these abstract authoritative and technical systems can - at least in the longer run - be a powerful source of trust.

Institutional trust is rooted in a transfer of an organization's control capacity from the level of individual to the level of collective decision. This form of trust emerges where one social actor offers a pre-commitment to another actor vis-à-vis specific institutional arrangements that constitute a world of shared meaning and normative rules of behaviour within organizations. This form of trust - as described in section 2.1 of this chapter - draws on the institutionalised patterns of the division of work duties and responsibilities as well as other elements of the structural inventory of the organization to 
which individual actors inevitably have to orient their expectations when interacting with one another. Although the rules that are incorporated in the structural arrangements of the organization may privilege some individuals while they restrict others in their chances to influence collectively binding decisions, they appear as a de-personalised and legitimised institutional order. Thus, they have normative power over expectations and interaction between the individual members of the organization, largely irrespective of their situational interests and the resources they might be able to mobilise in order to promote their particularistic interests. Because institutions are blind to individuals' opportunistic interests and the temporary availability of individually attributable resources of power, they can provide an important basis for the constitution of trust within organizations.

The structural inventory of the organization seems to be particularly relevant with regard to the amount of trust that it can swiftly produce among its members. If there exist powerful institutional rules to control the behaviour of individuals within organizations, these can absorb risk and increase the chance that trust becomes a preferred mechanism to co-ordinate social actors' expectations and interaction. Trust based on organizational institutions is in principle a home-bred phenomenon, constitutively produced within the boundaries of the organization. It can thus vary greatly from organization to organization. In contrast, system trust is mostly a phenomenon which originates in the external environment from where it reaches into the internal world of the organization.

As mentioned above, the characteristics of the national or regional business system in which an organization operates has a strong impact on the quality of intraorganizational relations (Whitley 1999; Sorge 1996; Streeck 1997). Thus, it can significantly foster the development of system trust relevant for the organiztion's internal activities (Bachmann 2002). At the same time, it can be assumed that this external environment also has a strong impact on the conditions under which institutional trust is generated within the organization. In highly regulated territorial business systems, organizations are likely to adapt their internal structures to the business environment in so 
far as they place specific emphasis on generalised rules and standardised procedures to attain their organizational goals and to realise their strategies. In reverse, situational decision-making in which the idiosyncrasies of individuals become influential are generally more likely to occur in organizations which operate in national and regional business systems that are characterised by a weak form of structural regulation and a low level of trust (Fox 1974; Bachmann 2001).

\subsection{Power in organizations}

Without doubt, trust is a social capital (Bourdieu 1979; Coleman 1990) which can become very valuable with regard to an organization's strategic competitiveness. It can considerably contribute to saving on transaction costs, speed up business processes and produce a work atmosphere which can be conducive to the innovativeness and creativeness of the organization's management and workforce. Thus, when compared to other means of fulfilling the same function, e.g. power or money, trust can be deemed a highly attractive mechanism to co-ordinate social relationships (Bradach and Eccles 1989). However, it cannot be ignored that there are also disadvantages to over-reliance on this co-ordination mechanism. Personal trust, in particular, is fragile and can break down without any chance of being quickly restored. In similar vein, it cannot be excluded that under certain conditions - institutional trust fades away where organizations go through periods of severe crisis (Kern 1998). Even system trust may turn out not to be completely safe against erosion as could be illustrated with reference to large-scale technological disasters such as Chernobyl or the gradual decline of the charismatic leadership model in the past three decades or so.

Looking at these problems that can occur with trust, it is worth considering other mechanisms which might also be utilised for the co-ordination of internal activities of the organization. For example, power can be assumed to be a mechanism which - as counterintuitive as it may seem - works on the basis of principles quite similar to those involved 
when trust is present. At the heart of both of these mechanisms lies a process in which one social actor selects specific assumptions about the future behaviour of another actor. In this respect, there is no difference between a trusting actor and a powerful actor. Each of them makes such a selection knowing that other choices are equally possible. Similar to a trustee, a (potentially) power accepting actor is - at least in principle - free to choose whether or not he will behave according to what the powerful party sees as a preferable way of dealing with each other in the future. However, the powerful actor does not select a positive assumption about the other party's future behaviour, as a trustor does. Rather, he selects a negative possibility of how the (potentially) power accepting actor could behave and presents it to him as a choice that would not be in either party's interest and hence as a possibility that should be avoided. From an analytical point of view, the result is not altogether different from what trust can achieve in a social relationship. Each of the two mechanisms can provide an effective solution to the problem of co-ordinating social actors' activities.

Also, as in the case of a trust-based relationship, any calculation that the (potentially) power exerting and accepting actors may be inclined to make must necessarily remain incomplete and imprecise. If the sanctions connected to the negative hypothetical assumption that the powerful actor has selected with regard to the power accepting actor's behaviour need to be mobilized, he has already lost his power and the quality of the relationship - if it does not simply end at this stage - takes on the form of coercion or violence (Clegg 1989). In the case of this event, power collapses similar to the breakdown of trust when legal and/or explicit sanctions are activated against cheaters. The similarities between the two mechanisms of co-ordinating expectations and interaction of organizational actors are, thus, quite striking. This, however, is not to say that there are no differences at all (Luhmann 1979).

The decision to use power as the preferred means of co-ordinating expectations and interaction between social actors in an organizational context buys into risk just as the decision to trust would do. But power does - at least in normal circumstances - not 
have the same moral weight that trust has. Power is, in this respect, generally more robust and one can expect that if power breaks down, this does usually not imply the same disastrous effects on inter-personal relationships and/or the organizational climate, as the disappointment of trust is likely to produce. This can be seen as an important advantage of power and one may conclude that power thus suggests itself as the preferable option for co-ordinating social actors' expectations and interaction in many situations, particularly where trust, from a potential trustor's point of view, appears too risky. In this case, a potential trustor might well prefer using his resources of power, pre-supposing - of course - that he has (a sufficient quantity of) these available. They can have the form of social reputation, privileged access to specific knowledge, superior communication skills etc. Whenever a (potential) trustor finds that he might foster his interests with less effort, faster and/or with less risk if he decides to draw on his resources of power, one should assume that he will in fact take this option disregarding the positive effects that a trustbased relationship might yield. The question of whether trust or power appears as the preferable option to the proactive party of the relationship might also depend on the psychological disposition of the individual actors and the existing and/or expected dynamics in an ongoing relationship (Nooteboom 2002b). By and large, however, this prediction should hold true if there are no exceptional extra- or intra-organizational factors which might additionally influence social actors' decisions.

To conclude, on the one hand, trust can be betrayed and - if this happens - the relationship between two individuals is likely to be destroyed for a long period of time. On the other hand, power can also be challenged. If this occurs it is likely that open conflict will be the result which may do considerable harm not only to the specific relationship between two individual actors but also to the organization as a whole. In usual circumstances, the advantages of a relationship that is predominantly based on trust are likely to supercede the possible advantages of a power-based relationship. Trust is a highly effective lubricant in many relationships which may increase with using it (Hirschman 1984). Power, by way of contrast, has generally a lower value as social 
capital and can hardly produce any self-controlled dynamics. There are, however, numerous cases where a powerful (potential) trustor has good reasons to consider power as his first choice. It may minimise risk more effectively and facilitate the alignment of other views with his own ideas in a more efficient manner.

\section{Two different trust/power control patterns}

In practice, the distinction between trust and power is a lot less sharp than it may seem at the analytical level. In fact, social relationships within (and between) organizations are normally based on a combination of both of these mechanisms. The empirically interesting question is often simply whether trust or power is dominant over the other mechanism in a specific relationship. In this - and only this! - sense one can speak of alternative options between which an individual actor can choose provided that both mechanisms are available to him at all. The latter, of course, is not always the case. Where, for example, a subordinate actor has no or little resources of power to draw on, the choice between trust and power is virtually non-existent for him. In such a situation this actor may hope that the powerful party will offer trust to be used as the central coordination mechanism in the relationship. But, evidently, it will be the powerful actor who will have the choice between running the risk that his pre-commitment may be misused by the potential trustee and relying on the assumption that the potentially power accepting party will actually take the fact that he has significant resources of power available as a good reason to acknowledge his claim. Thus, it largely depends on social status and situational circumstances whether or not a social actor will have a serious choice. Of course, theoretically one can assume that a powerless actor is always free to refuse acceptance of the powerful actor's selection of negative possibilities as regards his future behaviour and to favour, instead, an option which has been presented to him as one which should be avoided. But this has little relevance for the empirical world. Both parties are simply not equal in their chances of deciding which co-ordination mechanism 
should be dominant in the relationship. Rather, it seems that it is invariably the powerful party that ultimately determines which specific mixture of trust and power will dominate the relationship. There are, of course, cases where each of the two parties can draw on significant resources of power which they may use against each other. But then, this mechanism dramatically decreases its effectiveness as a means of co-ordinating expectations and interaction within the organization. The possibilities of developing trust in relationships increase accordingly under these circumstances.

Where trust and power appear as more or less distinct options, it is likely that personal trust is the form of trust that is in debate. By contrast, in cases of system trust and institutional trust, it is hardly a question of individual choice whether trust or power should have more weight in a relationship. The latter observation, of course, raises the question then: what other kind of inter-relationship between these two mechanisms could also be considered as possible? The answer as such is simple: impersonal trust - in the form of system trust or institutional trust - and impersonal power can each appear as a precondition of the impact of the other mechanism on individual actors' behaviour. The underlying assumptions and the theoretical consequences of this notion, however, are a bit more challenging to unravel.

As has been explained above, internal institutions and structural arrangements in the environment of the organization can be deemed a prime source of trust at the level of inter-personal relationships. Largely irrespective of the situational circumstances, potential trustors will often find enough good reasons to assume that the risk of misplaced trust is low where the structural inventory and the systemic elements of the external world of the organization are stable and reliable. Under these conditions, trust is predominantly produced in a de-personalised manner and will thus mostly appear in the form of impersonal trust, i.e. as institutional trust and/or system trust. If this is the case, it can be assumed that the level of trust will generally be high within the organization. For a potential trustor, it would simply seem not sensible to believe that a potential trustee is very likely to behave in an unforeseen manner unless there are exceptional circumstances 
to be considered, which recommend special precaution. A potential trustee can simply be trusted with less risk when he acts within 'social structures in which it is in ... (his) interest to be behave trustworthily' (Coleman 1990, p. 111).

Such structures which bundle social actors' interaction along the lines of generally accepted behaviour can be interpreted as powerful with regard to relationships within organizations. Power in this sense is, of course, different from the form of power that is based on the resources an actor can individually draw on. This form of power is incorporated in the institutional inventory of the organization and/or the structures of the authoritative and expert discourses that reach into the organization from its external environment. This impersonal form of power can be seen as a precondition of the existence and development of institutional trust and system trust within the organization. In the face of institutional power and/or system power - to use a terminology that closely connects with the distinctions made above with regard to trust (section 2) - individual actors tend to recognize good reasons to assume that the risk of misplaced trust is low and that investing trust in their relationships with each other is preferable to relying on individual resources of power (always provided that this is a realistic option for one of them at all).

The latter marks a fundamental difference between strongly and weakly regulated organizations. Where institutional power and/or system power foster the development of impersonal trust between members of an organization, a generally high level of trust is likely to prevail in their relationships. If, in contrast, a low level of organizational regulation exists, individual actors have a choice between either putting more effort into developing trust at the inter-personal level or - which indeed is more likely to happen then - falling back on their individual resources of power. The development of personal trust - although often considered as in principle preferable - would often simply seem too costly in terms of time and effort to be made (Zucker 1986).

Within organizational contexts where highly generalised and powerful rules exist, individuals may find it relatively easy to develop trust (system trust and institutional 
trust) in their relationships while, paradoxically, the need for trust seems relatively low. Where a high level of impersonal trust is present social actors have fewer incentives to develop personal trust in their relationships. At the same time, they are also systematically discouraged from utilising their individually available resources of power. Attempts to extensively draw on the latter would at best be ignored within an organization built on strong institutional and/or systemic regulation. More realistically, an individual frequently questioning the structural order of the organization and insisting on using his individual resources of power to co-ordinate expectations and interaction with other individuals, would be seen as a person who is useless or even dangerous with regard to the organization's identity and stability. In contrast, under conditions of a low level of impersonal regulation the same behaviour may well appear as an acceptable - if not essential - means of co-ordinating activities within the organization. Where few generalised norms and standards of behaviour exist, individuals almost inevitably have to draw on individually attributable resources of power where - which is a likely case personal trust cannot be produced swiftly and in sufficient quantity. If they refused to do so, a serious lack of co-ordination of individuals' behaviour would be the unavoidable consequence and the organization as such would sooner or later cease to exist.

Against the background of this argument, two ideal-types of organizational regimes emerge:

- Strongly regulated organizations where power primarily exists in the form of abstract rules and procedures: This form of power (i.e. impersonal power) is highly conducive to the production of institutional trust and system trust within the organization. Individual social actors trust each other because the institutional inventory of the organization as well as the external environment in which it is embedded provides a reliable framework for individuals' expectations and interaction. In these organizations, a latent threat of collectively legitimised sanctions is always present but is rarely made explicit or even mobilised. 
- More flexible organizations where much depends on individuals' idiosyncratic interests and the situational circumstances in which they make their decisions: In these organizations, individuals develop trust in their relationships primarily on the basis of inter-personal contacts. These play a vital role in co-ordinating expectations and interaction between the members of the organization. But as developing trust in the form of personal trust requires considerable efforts on the part of the individual actors and may, even when these efforts are made, still seem quite risky, organizational actors will often find it preferable or even unavoidable to draw on their resources of personal power to achieve a sufficient level of co-ordination of activities within the organization.

These ideal-typical reconstructions of organizational regimes mark the two ends of the scale whereas empirical cases can be expected to be located more at medium positions. System trust, in particular, is a form of trust which is rooted in anthropological conditions of human behaviour and/or the cultural basis of the business system in which the organization's identity is embedded. Irrespective of whether a highly or a weakly institutionally regulated organization is concerned, none of these is likely to exist without any system trust. At the same time, impersonal forms of power and trust have lost part of their impact on individuals' behaviour in the past three decades or so. Contemporary organizations, in other words, tend to move away from the traditional model of strong and bureaucratic regulation and foster flexibility as well as more decentralised processes of decision making. These developments are directly connected to the rediscovery of personal relationships and - in particular - personal trust in the post-bureaucratic organization (Grey and Garsten 2001). Thus, it can be concluded that system trust plays a stabilising role in weakly regulated organizations while even in strongly regulated organizations it has a decreasing potential to completely absorb individual actors' agency. 
The analysis of trust and power as two central mechanisms of co-ordinating relationships between individual social actors within an organizational context leads to the conclusion that - depending on the forms of trust and power and their specific combination - two distinct patterns of organizational control can be reconstructed. In strongly regulated organizations impersonal forms of trust and power tend to link into each other in such way that powerful intra-organizational and environmental structures breed trust between individual actors in a highly efficient manner. In a weakly regulated organization, by contrast, individual efforts to establish co-operation between relevant actors in the organization become more important. In this case, individuals often see trust and power as two different mechanisms to draw on when interacting with one another. Often, power is then preferred since trust may well promise many advantages for a relationship but is also quite awkward to build without strong impersonal safeguards.

The central aim of this chapter was to present a conceptual approach to analysing different regimes of organizational control. The argument presented above is thus based on analytical conceptualizations rather than empirically existing cases. The latter, of course, greatly vary over history and different cultural backgrounds. Nonetheless, however, in order to gain a deeper understanding of how organizations function and what strategies might be useful when strategic interventions are considered, the conceptual differentiation of the two suggested modes of organizational governance may be helpful as an analytical framework. In a neo-realistic view (Layder 1997; Reed 2001), these ideal-typical patterns of control might be understood as 'generative mechanisms' which do not determine the ways of (re-)producing and transforming social relationships within organizations. But they certainly do provide indispensable channels and viable configurations of co-ordinated interaction between individuals pursuing their interests in the context of organizational arrangements. 
Acknowledgements

I am particularly thankful to Bart Nooteboom, Gerry Redmond, Frederique Six, Arndt Sorge and Arjen van Witteloostuijn for their stimulating comments on earlier versions of this paper.

References

Bachmann, R. (2000), 'Die Koordination und Steuerung interorganisationaler Netzwerkbeziehungen über Vertrauen und Macht', in Jörg Sydow and Arnold Windeler (eds), Steuerung von Netzwerken. Konzepte und Praktiken, Opladen: Westdeutscher Verlag, pp. 107-125.

Bachmann, R. (2001), 'Trust, Power and Control in Trans-Organizational Relations', Organization Studies 22 (2), pp. 337-365.

Bachmann, R. (2002), 'The Role of Trust and Power in the Institutional Regulation of Territorial Business Systems', in Thomas Brenner/Dirk Fornahl (eds), The Influence of Co-operations, Networks and Institutions on Regional Innovation Systems, Cheltenham: Elgar.

Bradach, J.L. and R. G. Eccles (1989), 'Price, Authority, and Trust: From Ideal Type to Plural Forms', Annual Review of Sociology 15, pp. 97-118.

Bourdieu, P. (1979), La Distinction. Critique sociale du jugement, Paris: Les éditions de minuit.

Clegg, S. (1989), Frameworks of Power, London: Sage. 
Coleman, J. (1990), Foundations of Social Theory. Cambridge, M.A.: Belkamp Press.

Ebers, M. (1997) (eds), The Formation of Inter-organizational Networks, Oxford: Oxford University Press.

Fox, A. (1974), Beyond Contract: Work Power and Trust Relations, London: Faber.

Grey, C. and C. Garsten (2001), 'Trust, Control and Post-bureaucracy', Organization Studies 22 (2), pp. 229-250.

Giddens, A. (1990), The Consequences of Modernity, Stanford: Stanford University Press.

Hirschman, A.O. (1984), 'Against parsimony: Three Easy Ways of Complicating Some Categories of Economic Discourse', American Economic Review 74, pp. 88-96.

Kern, H. (1998), 'Lack of trust, surfeit of trust: Some causes of the innovation crisis in German industry', in Christel Lane and Reinhard Bachmann (eds), Trust Within and Between Organizations. Conceptual Issues and Empirical Applications, Oxford: Oxford University Press, pp. 203-213.

Lane, C. and R. Bachmann (1998), Trust Within and Between Organizations. Conceptual Issues and Empirical Applications, Oxford: Oxford University Press.

Layder, D. (1997), Modern Social Theory, London: University College London Press.

Luhmann, N. (1979), Trust and Power, Chichester: Wiley. 
Luhmann, N. (1984), Soziale Systeme. Grundriß einer allgemeinen Theorie, Frankfurt/Main: Suhrkamp.

Luhman, N. (1988), 'Familiarity, Confidence, Trust: Problems and Alternatives', in Diego Gambetta (ed.), Trust. Making and Breaking Cooperative Relations, Oxford: Blackwell, pp. 94-108.

Nooteboom, B. (2002a), Trust: Forms, Foundations, Functions, Failures and Figures, Cheltenham: Elgar.

Nooteboom, B. (2002b), 'The Trust Process', in this volume.

Powell W. W. and P.J. DiMaggio (eds) (1991), New Institutionalism in Organizational Analysis, Chicago: Chicago University Press.

Reed, M. (2001), 'Organization, Trust and Control: a Realist Analysis', Organization Studies 22 (2), pp. 201-228.

Scott, W.R. (1995), Institutions and Organizations, Thousand Oaks: Sage.

Simmel, G. (1950), The Sociology of Georg Simmel, ed. by K. H. Wolff, New York: Free Press.

Sorge, Arndt (1996), 'Societal effects in cross-national organization studies: conceptualizing diversity in actors and systems', in Richard Whitley and Peer Hull Kristensen (eds), The changing European firm. Limits to convergence, London: Routledge, pp. 67-86. 
Streeck, Wolfgang (1997), 'German capitalism: Does it exist? Can it survive?', in Colin Crouch and Wolfgang Streeck (eds.), Political Economy of Modern Capitalism, London: Sage, pp. 33-55.

Sydow, J. (1998), 'Understanding the Constitution of Interorganizational Trust', in Christel Lane and Reinhard Bachmann (eds), Trust Within and Between Organizations. Conceptual Issues and Empirical Applications, Oxford: Oxford University Press, pp. 3163.

Whitley, Richard (1999), Divergent capitalisms: the social structuring and change of business systems, Oxford: Oxford University Press.

Wittek, R. (2002), 'Norm Violations and Informal Control in Organizations. A Relational Signaling Perspective', in this volume.

Zucker, L. (1986), 'Production of Trust: Institutional Sources of Economic Structure 1940-1920', Research in Organizational Behaviour 8, pp. 53-111. 